\title{
Management of Cervical Intra Epithelial Neoplasia by Loop Electrosurgical Excision Procedure in a Low Resource Country: An Experience from the Yaoundé General Hospital, Cameroon
}

\author{
Jean Dupont Kemfang Ngowa1,2*, Anny Ngassam², Jovanny Fouogue Tsuala², \\ Juny Metogo' ${ }^{2}$ Zacharie Sando $^{3}$, Angèle Kabeyene ${ }^{3}$, Jean Marie Kasia ${ }^{1,2}$ \\ ${ }^{1}$ Obstetrics and Gynecology Unit, Yaoundé General Hospital, Yaoundé, Cameroon \\ ${ }^{2}$ Department of Obstetrics and Gynecology, Faculty of Medicine and Biomedical Sciences, \\ University of Yaoundé I, Yaoundé, Cameroon \\ ${ }^{3}$ Department of Pathology, Faculty of Medicine and Biomedical Sciences, University of Yaoundé I, \\ Yaoundé, Cameroon \\ Email: *jdkemfang@yahoo.fr
}

Received 21 July 2015; accepted 22 August 2015; published 25 August 2015

Copyright (C) 2015 by authors and Scientific Research Publishing Inc.

This work is licensed under the Creative Commons Attribution International License (CC BY).

http://creativecommons.org/licenses/by/4.0/

(c) (i) Open Access

\begin{abstract}
Background: Cervical cancer is the third most common cancer worldwide, and $80 \%$ of cases occur in the developing world. A critical component of effective cervical cancer screening programs is the ability to offer women appropriate and effective treatment for cervical intra epithelial neoplasia (CIN). Objectives: This study aimed at assessing the primary experience of management of CIN by Loop Electrosurgical Excision Procedure (LEEP) in a low resource country. Methods: We carried out a descriptive cross sectional study at the Yaoundé General Hospital in Cameroon. Results: Twenty three cases of CIN were treated by LEEP. Mean age of patients was $40.5 \pm 9.9$ years. Six (26.1\%) patients were infected by the Human Immunodeficiency Virus (HIV). LEEP was indicated in $21(91.30 \%)$ cases for CIN2 and CIN3. The mean duration of the surgical procedure was $10 \pm 3$ minutes. There was one (4.3\%) complication (persistent cervical bleeding). Surgical margins were negative for dysplasia or invasive carcinoma in $18(78.26 \%)$ cases and non-applicable in 5 $(21.73 \%)$ cases (thermal artefacts of margins and cervicitis without CIN). One patient with micro invasive carcinoma on post-operative histology was treated by total hysterectomy. Cervical cytology was normal at 6 months post LEEP for 15 cases out of $16(93.8 \%)$ patients who performed the test. One woman achieved pregnancy and delivered a term baby. Conclusion: Treatment of CIN by ${ }^{*}$ Corresponding author.
\end{abstract}

How to cite this paper: Ngowa, J.D.K., et al. (2015) Management of Cervical Intra Epithelial Neoplasia by Loop Electrosurgical Excision Procedure in a Low Resource Country: An Experience from the Yaoundé General Hospital, Cameroon. Open Journal of Obstetrics and Gynecology, 5, 481-486. http://dx.doi.org/10.4236/ojog.2015.59070 


\title{
LEEP is feasible, safe and effective in our setting.
}

\section{Keywords}

\author{
Cervical Cancer, Cervical Intraepithelial Neoplasia, LEEP, Screening Cervical Cancer, \\ Low Resource Country
}

\section{Introduction}

Cervical cancer is the third most common cancer worldwide, and $80 \%$ of cases occur in the developing world. It is the leading cause of death from cancer among women in developing countries, where it causes about 190,000 deaths each year [1]. According to the World Health Organisation, rates of the cervical cancer are highest in South and Central America, sub-Saharan Africa, and south and south-east Asia, where it is the most or second most common cancer among women [2]. In Cameroon, according to GLOBOCAN 2012 estimation, cervical cancer is the second gynecologic cancer after breast cancer. There were 1993 new cases in 2012 with a crude rate of 19.4 per 100,000 women [3].

In developed countries, initiation and sustenance of cervical cytology programmes involving the screening of sexually active women annually, or once in every 2 to 5 years, have resulted in a large decline in cervical cancer incidence and mortality over the last 40 to 50 years [2]. The aim of these screening programmes is to detect cervical intra epithelial neoplasia (CIN) and to treat them before they progress to invasive cancer [2]. A critical component of effective cervical cancer screening programs is the ability to offer women appropriate, effective treatment for precancerous cervical lesions, thereby reducing overall cervical cancer incidence and mortality [4]. There are several options available for treating precancerous lesions. Ablative methods, such as cryotherapy, cold coagulation, laser vaporization, and electrosurgery (cauterization), destroy the abnormal cervical tissue. Excisional methods, such as Loop Electrosurgical Excision Procedure (LEEP), remove the abnormal tissues. In many developing countries, however, clinicians must still rely on inpatient methods such as cone biopsy and hysterectomy to treat dysplasia. Although LEEP involves more equipment and supplies, it removes diseased tissue and provides a tissue specimen for analysis, reducing the possibility of overlooking invasive cancer [5]. This study's aim was to assess the primary results of our series of 23 cases of CIN treated by LEEP at the Yaoundé General Hospital in Cameroon.

\section{Methods}

We carried out a cross sectional study at the Gynecology/Obstetrics unit of the Yaoundé General Hospital. The period of study was from January 10, 2013 to February 26, 2015. Institutional ethical clearances were obtained. We retrieved all complete files of women who underwent LEEP for cervical intra epithelial neoplasia. The following data were collected using a pretested anonymous technical form: age, parity, age at first sexual intercourse, cumulated number of male sexual partners, HIV serology, pre-operative histological diagnosis (cervical biopsy specimen), type of anaesthesia, duration of surgery, post-operative histological diagnosis (LEEP specimen), histological status of surgical margins, post-operative complications, surgical wound healing (at 6 weeks and at 3 months), and post-operative cervical cytology (pap smear) at 6,12 and 18 months. Descriptive statistics were computed using Microsoft excel 2007 software.

\section{Results}

Twenty three cases of cervical dysplasia manage by LEEP in our institution were included in this study. Mean age of patients who underwent LEEP was $40.5 \pm 9.9$ years. Mean parity was $3.2 \pm 2.4$ term deliveries. Mean cumulated number of male sexual partners was $4 \pm 2$. Six cases out of 23 (26.1\%) were women infected by the Human Immunodeficiency Virus (HIV).The patients in this study had not realized the test of human papilloma virus (HPV). The moderate cervical intra epithelial neoplasia (CIN2) and severe cervical intra epithelial neoplasia (CIN3) were the main indications (21/23 cases) for LEEP (Table 1). All cases of LEEP were performed under general anaesthesia. The mean duration of the surgical procedure was 10 minutes $+/-3$. Figure 1 shows the 


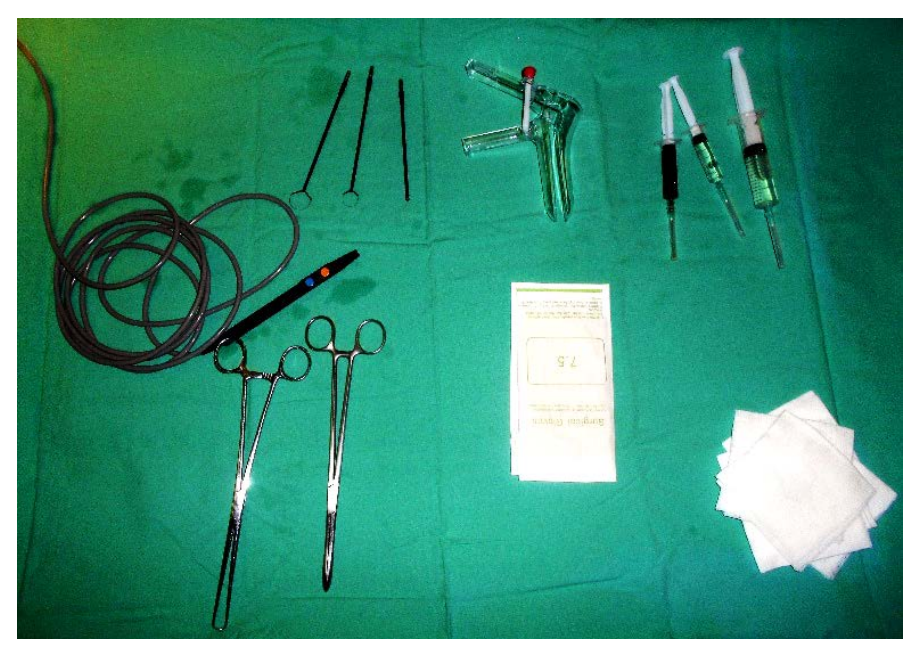

Figure 1. A view of the surgical table in the LEEP.

Table 1. Distribution of patients with respect to the indication for Loop Electrosurgical Excision Procedure.

\begin{tabular}{ccc}
\hline \multirow{2}{*}{ Indications for LEEP } & \multicolumn{2}{c}{ Patients treated by LEEP, N = 23 } \\
\cline { 2 - 3 } Persistent CIN1 & $\mathrm{n}$ & $\%$ \\
CNI2 & 1 & 4.34 \\
CIN3 & 10 & 43.47 \\
Normal histology with HSIL \\
at cytology
\end{tabular}

LEEP: Loop Electrosurgical Excision Procedure; CIN: Cervical Intraepithelial Neoplasia; HSIL: High-grade Squamous Intraepithelial Lesion.

instruments that we used to perform LEEP. Figure 2 shows the aspects of cervix before and after LEEP and cervix specimen of LEEP. Only one out of 23 (4.3\%) women had slight, persistent bleeding of the cervix immediately after conisation as complication. This bleeding was promptly treated by one point of suture ligation. The duration of hospital stay was one day for all women.

Table 2 shows the post-operative histology. Seven of the 10 cases (70\%) of CIN2 and 6 of the 10 cases of CIN3 at pre-operative histology were confirmed at postoperative histology. Operative margins were dysplasia free in 18 (78.26\%) cases and non-applicable in 5 (21.73\%) cases due to the moderate or severe thermal artefacts in 2 cases, and cervicitis without dysplasia in 3 cases.

No infection or haemorrhage was noted during the follow up. Complete cervical wound healing was achieved in all participants within 12 weeks following LEEP. No case of cervical stenosis was recorded. Cervical cytology was normal at 6 months post LEEP for 15 cases out of 16 (93.8\%) patients who performed the test. One woman had ASCUS (Atypical Squamous Cells of Unknown Significance) which was normal at 12 months following LEEP. One woman achieved pregnancy and delivery a term baby. One woman with micro-invasive cervical carcinoma at post-operative histology with surgical margins non applicable underwent total abdominal hysterectomy and the post-operative histology was normal.

\section{Discussion}

The mean age ( $40.5 \pm 9.9$ years) of women undergoing LEEP in our series is similar to a previous study in rural Cameroon (40.0 years) [6]. The mean age of patients with CIN in this study is consistent with 46 to 53 years of mean age at diagnosis of cervical cancer reported in Cameroon, assuming a latency of 10 - 15 years between CIN and cancer [7]-[10]. The mean parity of women in our study was $3.2 \pm 2.4$. This result is close to mean parity of five reported by Nkegoum et al. in 92\% of 946 Cameroonian women with CIN in their study [11]. 


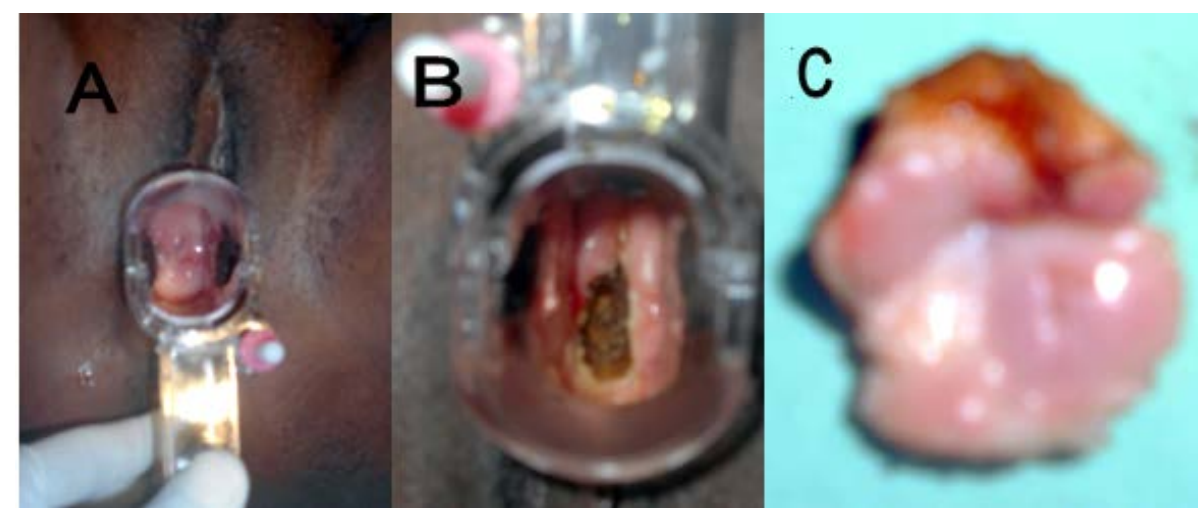

Figure 2. (A) Cervix before LEEP, (B) cervix after LEEP; (C) cervix specimen of LEEP References.

Table 2. Distribution of patients with respect to post-operative histology.

\begin{tabular}{lll}
\hline \multirow{2}{*}{ Post-operative histology } & \multicolumn{2}{l}{ Patients treated by LEEP; $\mathbf{N}=\mathbf{2 3}$} \\
\cline { 2 - 3 } Cervicitis without dysplasia & $\mathrm{n}$ & $\%$ \\
CIN1 & 3 & 13.04 \\
CNI2 & 6 & 26.08 \\
CIN3 & 7 & 30.43 \\
Micro invasive carcinoma & 6 & 26.08 \\
Operative margins & 1 & 4.34 \\
Negative & & \\
Non applicable & 18 & $78.26 \%$ \\
\hline
\end{tabular}

LEEP: Loop Electrosurgical Excision Procedure; CIN: Cervical Intraepithelial Neoplasia.

Several studies have found that HIV infected women are at higher risk of cervical precancerous lesions than those without infection, with Odds Ratios in the range of 4.1 to 11.0 [12]-[14]. Indeed it is thought that the immune impairment due to HIV infection will lead to the persistence of Human Papilloma Virus's infection which in turn will lead to precancerous lesions of the cervix [15]. In accordance with the data in literature, this study revealed a higher prevalence of HIV infection (26.1\%) among patients with CIN than the national HIV prevalence among adult women estimated to 5.6\% [16]. Hence, there is need to improve the cervical cancer screening among HIV infected women.

In developing countries, intra epithelial neoplasia is often treated with aggressive approaches such as cone biopsy or hysterectomy rather than with more appropriate outpatient approaches such as LEEP or cryotherapy [5]. Our study demonstrated that LEEP can be performed in our setting successfully in the treatment of cervical intra epithelial neoplasia. Excisional treatment methods such as LEEP have the advantage of providing tissue specimens for histopathological diagnosis, thereby reducing the possibilities of incomplete eradication of precancerous cells [4]. In this study, post-operative histology of one case of LEEP revealed micro invasive carcinoma which was treated by total hysterectomy. LEEP can be done as an office procedure under local anesthesia [17]. In our institution, all cases of LEEP were done as inpatient under general anesthesia. This could be explained by the fact that this technique had just been introduced in our practice and the team needed to acquire an experience before moving to a more simplified procedure as outpatient. The other reason could be the difficulty for some patients in the context of developing countries to return to the hospital at any time if there is an immediate complication. Complications are not common following LEEP and occur in about $1 \%$ to $2 \%$ of women. These may include excessive bleeding, infection, or narrowing (stenosis) of the cervical os [18]. Only one woman (4.3\%) had a complication and it was an early post-operative bleeding. The rate of bleeding as acompli- 
cation in this study is similar to the $4.9 \%$ and $5.4 \%$ reported by other authors [17]-[19].

One limit of this study is the small sample size which can constitute a selection bias. However, the merit of this study is to provide an idea about the feasibility of the treatment of CIN by LEEP in low resource setting.

\section{Conclusion}

The results of this study show that treatment of CIN by LEEP is feasible, safe and effective in our setting. However, adequate training is essential to ensure effective treatment.

\section{References}

[1] Pisani, P., Parkin, D.M., Bray, F. and Ferlay, J. (1999) Estimates of the Worldwide Mortality from 25 Cancers in 1990. International Journal of Cancer, 83, 18-29 [Published Erratum Appears in International Journal of Cancer, 83, 1999, 870-873].

[2] Sankaranarayanan, R., Budukh, A.M. and Rajkumar, R. (2001) Effective Screening Programs for Cervical Cancer in Low- and Middle-Income Developing Countries. Bulletin of the World Health Organization, 79, 954-962.

[3] World Health Organization (2012) GLOBOCAN 2012: Estimated Cancer Incidence, Mortality and Prevalence Worldwide in 2012. http://globocan.iarc.fr/Pages/fact_sheets_population.aspx

[4] (2015) Treating Precancerous Cervical Lesions-IARC Screening.

[5] Sherris, J., Herdman, C. and Elias, C. (2001) Cervical Cancer in the Developing World. West Journal Medicine, 175, 231-233. http://dx.doi.org/10.1136/ewjm.175.4.231

[6] Tebeu, P.M., Sandjong, I. and Nkele, N. (2005) Lésions précancéreuses du col utérin en zone rurale: Etude transversale. Médecined' Afrique Noire, 52, 27-31.

[7] Yomi, J., Monkam, G., Tagni, D. and Doh, A.S. (1999) Anatomical-Clinical Presentation and Prognostic Factors in Cancers of the Cervix at the General Hospital of Yaoundé. West African Journal of Medicine, 18, 20-23.

[8] Mbakop, A., Yomi, J., Yankeum, J., Nkegoum, B. and MouelleSone, A. (1997) Cancer Localisation in Men and Women Aged over 50 in Cameroon. Bulletin du Cancer, 84, 1119-1122.

[9] Tebeu, P.M., Petignat, P. and Mhawech-Fauceglia, P. (2009) Gynecological Malignancies in Maroua, Cameroon. International Journal of Gynaecology \& Obstetrics, 104, 148-149. http://dx.doi.org/10.1016/j.ijgo.2008.09.005

[10] Sando, Z., Fouogue, T.J., Fouelifack, Y.F., Fouedjio, J.H., Mboudou, E.T. and Essame, J.L.E. (2014) Profil des cancers gynécologiques et mammaires à Yaoundé-Cameroun. Pan African Medical Journal, 17, 28.

[11] Nkegoum, B., BelleyPriso, E. and Mbakop, A. (2001) Precancerous Lesions of the Uterine Cervix in Cameroonian Women. Cytological and Epidemiological Aspects of 946 Cases. Gynecologie, Obstetrique \& Fertilité, 29, 15-20. http://dx.doi.org/10.1016/S1297-9589(00)00024-2

[12] Temmerman, M., Tyndall, M.W., Kidula, N., Claeys, P., Muchiri, L. and Quint, W. (1999) Risk Factors for Human Papillomavirus and Cervical Precancerous Lesions and the Role of Concurrent HIV-1 Infection. International Journal of Gynecology \& Obstetrics, 65, 171-181. http://dx.doi.org/10.1016/S0020-7292(99)00043-0

[13] Moodley, J.R., Hoffman, M., Carrara, H., Allan, B.R., Cooper, D.D., Rosenberg, L., Denny, L.E., Shapiro, S. and Williamson, A.L. (2006) HIV and Pre-Neoplastic and Neoplastic Lesions of the Cervix in South Africa: A Case-Control Study. BMC Cancer, 6, 135. http://dx.doi.org/10.1186/1471-2407-6-135

[14] Hawes, S.E., Critchlow, C.W., Faye Niang, M.A., Diouf, M.B., Diop, A. and Touré, P. (2003) Increased Risk of High-Grade Cervical Squamous Intraepithelial Lesions and Invasive Cervical Cancer among African Women with Human Immunodeficiency Virus Type 1 and 2. Journal of Infectious Diseases, 188, 555-563. http://dx.doi.org/10.1086/376996

[15] Strickler, H.D., Burk, R.D., Fazzari, M., Anastos, K., Minkoff, H., Massad, L.S., et al. (2005) Natural History and Possible Reactivation of Human Papillomavirus in Human Immunodeficiency Virus-Positive Women. Journal of the National Cancer Institute, 97, 577-586. http://dx.doi.org/10.1093/jnci/dji073

[16] (2015) The 2011 DHSMICStradprelim_Draft1—Cameroon. Demographic and Health Survey and Multiple Indicators Clusters Survey. DHS-MICS 2011. http://www.statistics-cameroon.org/downloads/EDS-MICS11/DHSMICS_2011_preliminary_report.pdf

[17] Sutthichon, P. and Kietpeerakool, C. (2009) Perioperative Complications of an Outpatient Loop Electrosurgical Excision Procedure: A Review of 857 Consecutive Cases. Asian Pacific Journal of Cancer Prevention, 10, 351-354.

[18] Mitchell, M.F., Tortolero-Luna, G., Cook, E., Whittaker, L., Rhodes-Morris, H. and Silva, E. (1998) A Randomized Clinical Trial of Cryotherapy, Laser Vaporization, and Loop Electrosurgical Excision for Treatment of Squamous Intraepithelial Lesions of the Cervix. Obstetrics and Gynecology, 92, 737-744. 
http://dx.doi.org/10.1016/S0029-7844(98)00246-4

[19] Panna, S. and Luanratanakorn, S. (2009) Positive Margin Prevalence and Risk Factors with Cervical Specimens Obtained from Loop Electrosurgical Excision Procedures and Cold Knife Conization. Asian Pacific Journal of Cancer Prevention, 10, 637-640. 